\title{
THE NEW FACE OF ALTERNATIVE ASSESSMENT IN ACCOUNTING SCIENCES - TECHNOLOGY AS AN ANTHROPOMORPHIC STAKEHOLDER
}

\section{O. Swart*}

Department of Financial Intelligence

e-mail: swarto@unisa.ac.za / https://orcid.org/0000-0003-4046-9033

\section{C. Shuttleworth*}

Department of Management Accounting

e-mail: shuttcc@unisa.ac.za / https://orcid.org/0000-0001-6796-0530

*University of South Africa

Pretoria, South Africa

\section{ABSTRACT}

Worldwide, more and more higher education institutions are making use of online or distance education, due to the increasing demand for tertiary education. In this article, the problem addressed relates to the importance of technology as a stakeholder in alternative assessments for undergraduate accounting sciences modules in an online, non-venue-based, technologyenhanced environment. The purpose of this article is to demonstrate how technology, due to its importance and impact, acts similarly as a human stakeholder and should be treated as an anthropomorphic stakeholder in an online technology-enhanced environment, considering its powerful role. A qualitative approach was followed, and action research was used to develop a conceptual framework. This conceptual framework demonstrates how stakeholder theory could ensure the legitimacy of qualifications through identity verification of students in an online environment through improved performance and innovation potential. These findings contribute to the body of knowledge and due to its importance, technology could be considered as an anthropomorphic stakeholder in the creation, improvement, or restructuring of assessments at online educational institutions.

Keywords: accounting sciences, alternative assessment, anthropomorphic stakeholder, nonvenue-based assessment, online environment, open distance learning (ODL), open distance elearning (ODeL), stakeholder theory, technology, technology-enhanced, technology-supported

\section{INTRODUCTION}

"Technology can become the 'wings' that will allow the educational world to fly farther and faster than ever before - if we will allow it" - Jenny Arledge.

Education is a national priority and has the potential to reduce unemployment, alleviate poverty 
and minimise other inequalities through educational opportunities relevant to the market (The World Bank 2018). Due to the increasing demand for tertiary education, more and more higher education institutions (including contact universities) globally offer online or distance education. In 2017, the total number of students enrolled at tertiary education institutions worldwide, increased to over 220 million (UNESCO Institute for Statistics 2019). The high number of registered students in South Africa necessitates effectiveness, not only in teaching but also in the assessment of these students within a technology-enhanced environment (Padayachee, Wagner-Welsh, and Johannes 2018). The improvement of pass rates and throughput of these distance education students, as well as ensuring quality tuition and assessment in a technology-enhanced environment, is crucial to deliver successful graduates (Department of Higher Education and Training [DHET] 2014; Padayachee et al. 2018; Tung 2012). To ensure the security and academic integrity of courses, more and more institutions are integrating state-of-the-art technology in the online environment (Khare and Lam 2008; Padayachee et al. 2018; Waghid and Davids 2019).

Since online or e-learning has become increasingly accessible with the use of technology, universities are encouraged to expand their online learning, as most students cannot attend fulltime classes because they are employed or due to their geographical distance from a university (DHET 2013; Subotzky and Prinsloo 2011). Open distance learning (ODL) is where distance education methods are used to affect open learning purposes and principles (DHET 2014). The definition of ODL can be extended to ODeL (open distance e-learning), as it mostly hinges on the use of online or e-learning, whereby the utilisation of technology becomes an integral part of education.

Due to the global digital transformation, there is an increasing gap between accounting graduates' entry-level skills and skills needed in the workplace (Pincus et al. 2017; World Economic Forum [WEF] 2016). Higher-order skills, sometimes also referred to as critical thinking skills, are required to measure the reasoning, understanding and complex problemsolving acumen of accounting sciences students (Scully 2017). It is important to not only hone the technical skills and thinking skills of students, but also to instil lifelong learning skills.

International and South African professional accounting bodies (for example ACCA [Association of Chartered Certified Accountants]; CIMA [Chartered Institute of Management Accountants] and SAICA [South African Institute of Chartered Accountants]) already assess students by applying various online or electronic methods of assessment such as task-based simulations and case studies. These online assessments are alternatives to the traditional written summative examinations or assessments but are still venue-based, as they are completed in registered test centres (ACCA 2019b; CIMA 2018; NASBA [National Association of State 
Boards of Accountancy] 2016; SAICA 2018). Lecturers and students believe that online taskbased simulations and case studies (also referred to as open-book assessments), are more appropriate methods to assess students' knowledge (Kruger 2018). In this article, the importance of technology as a stakeholder in non-venue-based summative assessments for undergraduate accounting sciences modules in an online ODeL environment is demonstrated.

\section{LITERATURE REVIEW}

The related aspects pertinent to alternative assessments in a non-venue-based online environment - specifically in accounting sciences - are discussed in the literature review. In this article, the reference made to alternative assessments, specifically includes technologyenhanced or -supported, non-venue-based formative and summative assessments. The latest innovations and improvements in technology permit the use of information and communication technology (ICT) to provide the content more efficiently and effectively in an online environment and result in more interactive engagement in education (Council on Higher Education [CHE] 2014; Fengliang 2018). The development of ICT also allows for continuous non-venue-based assessments during the semester or academic year. Continuous assessments allow students to submit formative assignments online and receive online constructive feedback from lecturers or tutors throughout the tuition period (DHET 2014). Formative assessments take place during the tuition period and usually comprise assignments and self-assessments that contribute towards the achievement of the outcomes of a module. Most universities make use of non-venue-based formative assessments such as assignments or portfolios. Summative assessments were traditionally limited to examination venues (venue-based) and take place at the end of the tuition period as the final examination or evaluation, to determine whether the outcomes of a module have been successfully achieved (Chaudhary and Dey 2013; Dunn and Mulvenon 2009; South African Qualifications Authority [SAQA] 2014). If there is a high alignment between formative and summative assessments, continuous assessments can be successfully integrated or combined (De Lisle 2015). Both formative and summative assessments can be in the form of online non-venue-based technology-enhanced assessments.

Online assessments allow for regular, timeous and meaningful feedback to students (Meyen et al. 2002; Padayachee et al. 2018). Feedback on assessments should be constructive and timeous to contribute to the success of accounting students and is crucial for reflection on results achieved (Marriot 2009; McChlery and Visser 2009; Van Rooyen 2015). Types of alternative assessments can include take-home assessments (Norcini, Lipner, and Downing 1996), timed online assessments (Buchanan 2000; Oraifige, Heesom, and Felton 2009), portfolios (Meyen et al. 2002), e-portfolios (Alexiou and Paraskeva 2010; Meyen et al. 2002), 
webinars (Wang and Hsu 2008); peer review (Taylor, Ryan, and Pearce 2015; Watwood, Nugent, and Deihl 2009) and continuous assessments (Isaksson 2008). Lecturers and students believe that these alternative assessments are also a more appropriate method to assess students' knowledge, as it is in an open-book format that contributes to deeper learning and enforces lifelong learning (Kruger 2018).

Lifelong learning supports the development of cognitive skills (Pavela, McCabe, and McDuf 2017). Student learning can be enhanced with the use of creative forms of assessment such as self-assessment and peer review (Pavela et al. 2017). International and local professional accounting associations already administer online or electronic summative assessments to assess professional examinations at test centres (ACCA 2019a; CIMA 2018; SAICA 2016; 2018). Since these alternative assessments are venue-based, the identity of students can be verified by physically verifying their identity or student cards.

It is problematic to guarantee the identity of students in an online non-venue-based environment. However, rapid changes in technology during the Fourth Industrial Revolution (4IR), make automated academic integrity measures possible. Identity verification and authorship validation can be automated, when continuous and concurrent academic work and assessments are submitted, to ensure academic integrity (Amigud et al. 2017). Various types of advanced technologies are available, but it is very expensive and can include retinal scans, thermographs, fingerprint scans and voice recognition (Khare and Lam 2008). Plagiarismdetection services (such as Turnitin, VeriCite, PlagScan, Unicheck and UNPLAG) are available to check for similarity indexes or plagiarism by comparing documents with previously submitted documents that exist somewhere on a repository on the web (Khare and Lam 2008; Moodle 2019; Waghid and Davids 2019). To discourage students from cheating, plagiarising or making use of proxies, ghost writers or contract writers, a combination of plagiarismdetection measures should be put in place at educational institutions, especially in an online environment (Fisher et al. 2016; Waghid and Davids 2019; Xu, Kauer, and Tupy 2016). A ghost writer is usually a freelance person hired to write other people's assignments or assessments on their behalf, at a fee, resulting in students mispresenting it as their own work (Fisher et al. 2016; Waghid and Davids 2019). These unethical actions are referred to as academic misconduct.

Students must be made aware of the consequences of academic misconduct, the use of ghost writers or any other unethical transgressions, and that they will be held accountable for it (Carroll and Appleton 2001; Fisher et al. 2016; Jones, Reid, and Bartlett 2008). Honesty declarations or honour codes, proctoring sites and the monitoring of IP addresses should be considered in a technology-supported environment to reduce plagiarism or cheating with online assessments (Watwood et al. 2009). The use of honesty declarations statistically lowers the 
level of dishonesty by explaining academic misconduct or unethical behaviour to students, especially in the case of non-venue-based assessments (Khare and Lam 2008; Pavela et al. 2017).

Students are one of the most important stakeholder groups in an ODeL environment. In addition to students, other stakeholders can also influence the alternative assessment process in a distance learning environment. In the case of tertiary education, "stakeholders" refers to any internal or external stakeholders (such as academics, students, employers, government and professional bodies) with an interest in education and an influence on the institution (Bjørkquist 2009). Stakeholder theory is based on the ethical values in the administration of an organisation (Mitroff 1983). Freeman $(1984,25)$ defines a stakeholder as "any group or individual who can affect or be affected by the decisions and the achievement of corporate objectives". Stakeholder theory, therefore, indicates how various stakeholders influence the organisation (Freeman 1984; Mitroff 1983). The stakeholders' needs are used as the focus of any action and stakeholder theory has thus become a popular theory in organisations and institutions (Leisyte and Westerheijden 2014). Universities need to identify their stakeholders as well as their attributes to survive in a competitive market (Khanyile 2018). Power, legitimacy and urgency influence the significance of stakeholder claims, and as a result, stakeholders are defined as latent, expectant or definitive, depending on their influence on the organisation (Khanyile 2018; Mitchell, Agle, and Wood 1997).

According to Mitchell's model (Mitchell et al. 1997), the categories of stakeholders and their various attributes can be demonstrated according to the number of attributes they have. These attributes refer to power, legitimacy and urgency, which could influence the significance of stakeholder claims and could change for any specific entity (Mitchell et al. 1997). Depending on the number of attributes (power, legitimacy and urgency), stakeholders can, based on the influence they have, be defined as:

- latent stakeholders (with only one of the three attributes) and can be either dormant, discretionary or demanding stakeholders;

- $\quad$ expectant stakeholders (with two of the three attributes) and can be dominant, dependent or dangerous stakeholders; and

- $\quad$ definitive stakeholders (with all three attributes) (Mitchell et al. 1997).

The more attributes that are applicable, the more influence the stakeholder has. According to Mitchell's model (Mitchell et al. 1997), the following three attributes should be present in stakeholders to significantly influence an institution: 
- Power: The impact of professional accounting bodies as well as governing and other regulatory bodies is a very powerful attribute. According to Mitchell et al. (1997), a party with power can impose its will in a relationship by way of coercive, utilitarian or normative means. Technology can also be extremely powerful if the impact of the 4IR and innovations such as the advancement in the Internet of Things are considered.

- Legitimacy: If assessment is key to formal education, the legitimacy of qualifications is crucial to protect the integrity of the institution and to produce capable graduates. This is especially true in the case of technology-enhanced alternative non-venue-based assessments. This is in accordance with Suchman's $(1995,574)$ definition, namely "legitimacy is a generalised perception or assumption that the actions of an entity are desirable, proper, or appropriate within some socially constructed system of norms, values, beliefs, and definitions". The use of technology-enhanced systems to ensure identity verification of students, inter alia, can contribute to the legitimacy of qualifications.

- Urgency: The accelerated need for technology and continuous innovation is urgent given the 4IR and the rapid move to the Fifth Industrial Revolution (5IR) (Lindsay and Hudson 2019).

All three attributes are present in technology and due to its considerable influence on the ODeL institution, it enforces the view of technology presenting itself as an anthropomorphic stakeholder in the institution. The importance of technology in a virtual or online environment and specifically in an online assessment environment is crucial (Padayachee et al. 2018).

\section{Academic integrity towards legitimacy}

The use of online assessment in tertiary education is gaining momentum and technologyenhanced innovative methods should be considered to support and enhance the student experience in this regard (Padayachee et al. 2018). In the accounting sciences environment, case studies, problem-based learning and simulations are considered to be suitable assessment methods (Eloff 2016). The use of case studies in an online environment could enhance and develop the pervasive skills of students (Reyneke 2016). In addition, plagiarism is less likely to occur when case studies are used to assess students (Parle and Laing 2017; Rust 2002). Due to the integrated nature of case studies as an assessment method, it can also assist with identity verification and other academic integrity challenges (Rovai 2000).

Technological solutions and analytics should be implemented to reduce cheating and 
unethical behaviour in online assessment. More and more institutions are using analytics to ensure the security and integrity of courses (Khare and Lam 2008). The benefit of automated academic integrity measures is the continuous and concurrent validation of academic work and assessments submitted, resulting in both identity verification and authorship validation (Amigud et al. 2017). Academic integrity can be classified into three types, namely identity verification, verification of authorship, and monitoring and controlling the online environment with the use of information technology approaches, as shown in Table 1 (Amigud et al. 2017).

Table 1: Academic integrity approaches between venue-based and non-venue-based assessment

\begin{tabular}{|c|c|c|c|}
\hline $\begin{array}{l}\text { Type of academic } \\
\text { integrity }\end{array}$ & IT method used & Venue-based & Non-venue-based \\
\hline \multirow[t]{2}{*}{ Identity verification } & Biometrics & $\begin{array}{l}\text { - Fingerprint } \\
\text { - Valid identity } \\
\text { document, student } \\
\text { card, driver's licence }\end{array}$ & $\begin{array}{l}\text { - Verify identity via webcam } \\
\text { - Keystroke recognition (in } \\
\text { combination with honesty } \\
\text { declaration) } \\
\text { - Writing patterns }\end{array}$ \\
\hline & $\begin{array}{l}\text { Challenge questions } \\
\text { asked to verify } \\
\text { identification }\end{array}$ & Not applicable & Randomised challenge questions \\
\hline \multirow[t]{2}{*}{$\begin{array}{l}\text { Validation of } \\
\text { authorship }\end{array}$} & $\begin{array}{l}\text { Detection of } \\
\text { plagiarism }\end{array}$ & $\begin{array}{l}\text { Direct observation of } \\
\text { invigilator present }\end{array}$ & $\begin{array}{l}\text { - Algorithms measuring similarity } \\
\text { (e.g., Turnitin) } \\
\text { - Monitoring IP addresses } \\
\text { - Lockdown browsers }\end{array}$ \\
\hline & $\begin{array}{l}\text { Validation by } \\
\text { instructor }\end{array}$ & $\begin{array}{l}\text { Direct observation by } \\
\text { invigilator present }\end{array}$ & $\begin{array}{l}\text { Video streams analysing candidates } \\
\text { before an examination, while taking } \\
\text { the examination, or after the } \\
\text { examination }\end{array}$ \\
\hline \multirow[t]{2}{*}{$\begin{array}{l}\text { Monitoring and } \\
\text { control }\end{array}$} & Proctoring & $\begin{array}{l}\text { Computer laboratory or } \\
\text { venue with proctoring by } \\
\text { instructor or invigilator }\end{array}$ & $\begin{array}{l}\text { Student's own laptop or computer in } \\
\text { remote locations with remote } \\
\text { proctoring }\end{array}$ \\
\hline & Monitoring activities & $\begin{array}{l}\text { Direct observation by } \\
\text { invigilator present }\end{array}$ & $\begin{array}{l}\text { Video streams analysing candidates } \\
\text { while taking examinations }\end{array}$ \\
\hline
\end{tabular}

Source: Adapted by authors from Amigud et al. (2017)

While Amigud et al. (2017) summarise the different academic integrity methods and approaches, Table 1 was adapted to include a venue-based and non-venue-based allocation. The monitoring and control of identity verification and authorship validation ultimately contribute to academic integrity (Amigud et al. 2017).

\section{Identity verification}

Identity verification is crucial in an online (non-supervised) environment, especially where students are assessed on the results of non-venue-based assessments and where an increasing number of students could use proxies, ghost or contract writers to complete an online assessment on their behalf. By making use of technology-enhanced methods, more trust can be placed in the identity verification of students in an online environment. Fisher et al. (2016) 
propose that a student biometric profile should be created to enable voice, eye and face identification, finger or palm prints, or keystroke recognition. To verify the identity of the student, an honesty declaration (to assist with keystroke recognition), could form part of the biometric student profile. An honesty declaration is an attempt to discourage a student from cheating (Xu et al. 2016) and could statistically lower the level of dishonesty, as ethical behaviour is explained to the student to reduce misunderstanding (Khare and Lam 2008). In distance education, a biometrical profile is very important to verify a student's identity, specifically for high-stakes final examinations. The student profile can be linked to the identity management system of the institution by, for example, taking photos at registration and comparing it with the photo identification on the date of the assessment (Fisher et al. 2016; Von Grünigen et al. 2018).

\section{Validation of authorship}

Computer programs, such as Turnitin, use algorithms to compare documents against billions of internet documents. These programs can be used to ensure the originality of submitted assessments (Fisher et al. 2016; Jones et al. 2008; Khare and Lam 2008). Higher education institutions should also consider monitoring students' IP addresses to validate authorship (Watwood et al. 2009). Lockdown browsers can be used to limit students' access to other websites, documents, emails and other resources, but this is not feasible for non-venue-based students, because they are resourceful and may use a variety of devices at home (Fisher et al. 2016; Jones et al. 2008; Xu et al. 2016). In an online environment, these methods could be combined with the use of a camera to provide more surety. Remote access should also be blocked, to prohibit third parties to view and perform actions on the student's computer screen (Von Grünigen et al. 2018).

\section{Monitoring and control}

Institutions should consider making use of proctoring in an online environment (Watwood et al. 2009). Proctoring promotes ethical behaviour by ensuring that it is the actual student doing the assessment and not a proxy, ghost or contract writer. Students are more likely to cheat in un-proctored online formative and summative assessments than in proctored online formative and summative assessments (Arnold 2016; Hylton, Levy, and Dringus 2016; Von Grünigen et al. 2018). Daffin and Jones (2018), mentioned in their study that students perform better in an online summative assessment if it is not proctored, which may be an indication of cheating.

The proctoring process can be venue-based (with at least one invigilator at a venue) or non-venue-based (Fisher et al. 2016). 
Non-venue-based proctoring can be either live or recorded for evaluation at a later stage (Fisher et al. 2016). In the case of live proctoring, the student and his or her activities are continuously monitored online via a webcam and computer monitor. To authenticate the identity of the student, a student profile must be created, for instance at registration. After the proctor has verified the student's identity by comparing it to the original student profile, the student receives a password to allow access to the assessment. This process is expensive, especially in the case of large student numbers, because more proctors are needed for an extended time. With recorded proctoring, the content of students' screens is video recorded (Fisher et al. 2016; Von Grünigen et al. 2018). Unethical behaviour is then flagged by the system and studied for possible cheating by the invigilator at a later stage (Fisher et al. 2016).

\section{Methods to increase academic integrity}

The higher the academic integrity confidence level required, the higher the cost of implementing measures to confirm the academic integrity, because these measures are usually resource-intensive (Amigud et al. 2017). Computational data analytics measures, such as keystroke analysis, algorithms that measure similarity or patterns in text data, or analysis of video streams of candidates taking an examination (simulating invigilators), enhance identity and authorship verification (Amigud et al. 2017). Final summative examinations will usually require multi-layered authentication through identity verification, verification of authorship as well as constant monitoring and control during the assessment process (Amigud et al. 2017; Fisher et al. 2016). Specifically, in the case of high-stakes non-venue-based summative examinations, proctored examinations should be considered in combination with biometrics. Students should be monitored consistently by a live proctor to confirm the identity of the student and the validity of the academic content during the full period of completing the online assessment (Fisher et al. 2016; Von Grünigen et al. 2018).

In the case of non-venue-based assessments, Von Grünigen et al. (2018) propose that several technologies can be combined, and a lockdown browser can be used in combination with a webcam to include proctoring. Respondus LockDown Browser ${ }^{\circledR}$ is an example of a lockdown browser used to control the virtual online environment and can also offer virtual proctoring to monitor students via webcam (Respondus 2018). However, Stack (2015) found no significant differences between a group of students who wrote a traditional venue-based examination and another group who wrote an online examination through Respondus LockDown Browser ${ }^{\circledR}$. All these measures are used to ensure academic integrity, by making use of technological infrastructure. 


\section{Technology as a stakeholder}

Stakeholder theory incorporates various stakeholders that influence the institution. Various authors contributed to defining stakeholders over the years and can include any groups or individuals affected by decisions made by the institution (Freeman 1984). Attributes such as power, legitimacy and urgency could influence the significance of stakeholder claims on the organisation (Mitchell et al. 1997). The available literature on stakeholder theory has been limited to specific areas of information technology and only refers to individuals or groups within the organisation (Mishra and Mishra 2013). Mishra and Mishra (2013) conclude that stakeholder theory may influence technology.

\section{RESEARCH DESIGN}

To achieve the objective of the article, a comprehensive literature review was followed by qualitative interviews. Action research was applied and is an iterative process of identification, planning, action and evaluation and is usually used for exploratory, descriptive or action-related purposes (McNiff 2020; Mouton 2001; Saunders, Lewis, and Thornhill 2016). The characteristics of action research are that it is practical, focusing on change, an interactive cyclical process (of identification, planning, implementation and reflection), and driven by participation, to result in an inherently interactive form of knowledge development (Creswell 2005; Denscombe 2003; Saunders et al. 2016). In the identification phase, the review of the literature focused on the relevance and consistency of needs in the ODeL context. Understanding the ODeL context was important for the legitimacy of the article (Brinkmann and Kvale 2015). Understanding is a key characteristic of interpretivism while constructive knowledge is the focus in pragmatism (Goldkuhl 2012). A pragmatic approach was followed to determine whether the article had provided useful knowledge (Salmons 2015). A conceptual framework was developed based on the literature review.

As part of the action research, there were various iterations to evaluate the conceptual framework through further observation and action (Salmons 2015). It was done by conducting semi-structured one-on-one interviews with ODeL lecturers who have previously made use of non-venue-based formative and summative alternative assessments. Members of South African (e.g., SAICA) and international professional accounting bodies (e.g., ACCA and CIMA) were also interviewed through one-on-one interviews to evaluate the conceptual framework for consistency and practicality and amend it with the contributions from the data analysis. The final framework was presented after triangulation by way of document analysis of comments from students regarding their experiences on the practicality and effectiveness of summative 
alternative assessment as recorded in a report based on a research project previously conducted at an ODeL university.

Purposeful sampling was used to select first-, second- and third-year lecturers with at least three years' experience in ODeL in the main subject areas of accounting sciences. All these lecturers had previous experience in formative as well as summative alternative non-venuebased assessments. Purposeful sampling was also used to select members of professional accounting bodies. When a sample is intentionally selected for the most effective use of limited resources following the relevance and needs of the study, it is defined as purposeful sampling (Mason 2018; Palinkas et al. 2015; Salmons 2015). Purposeful sampling is a widely used qualitative research technique to identify and select information-rich cases applicable to the specific study (Palinkas et al. 2015; Patton 2015). Semi-structured interviews were conducted with these selected participants.

The trustworthiness of the qualitative data was established in terms of credibility, transferability, dependability and confirmability (Lincoln and Guba 1985; 2013). The interview schedule included key questions and allowed for comments to open the discussion with a few prompts to promote further in-depth discussions. Informed consent was obtained from ODeL lecturers, as well as from members of professional accounting bodies before the interviews commenced. Interviewees were informed that their privacy and confidentiality were guaranteed and that they could withdraw or choose not to participate at any time during the interview. The sampling, data gathering, and processing of the relevant data were undertaken in a manner that was respectful of the rights and integrity of all parties (Brinkmann and Kvale 2015).

All interviews conducted were recorded and transcribed, and were coded and analysed in ATLAS.ti ${ }^{\mathrm{TM}} 8$, a computer-assisted qualitative data analysis software program (CAQDAS). The researchers coded 22 interviews and made use of thematic analysis to identify, analyse and systematically interpret patterns of meaning (themes) from the qualitative data set (Braun and Clarke 2012; Clarke and Braun 2017). Thematic analysis assisted to make sense of meanings and experiences shared by the participants to identify what the common opinions and perceptions were (Braun and Clarke 2012). The researchers followed Saldaña's codes-to-theory model (Saldaña 2016). Both the coding and the model were validated by an independent second coder. In addition, second coding and qualitative model consensus meetings took place (Barbour 2001).

The final list of codes was established at 186, which were combined into data categories and finally consolidated into five themes. The themes included ODeL institutions, assessment in accounting sciences, accreditation, legitimacy and technology. One aspect mentioned repeatedly by the interviewees, was the importance of identity verification of students in an 
online ODeL environment contributing to the legitimacy of qualifications. Technology can assist with identity verification and it was very clear from the data analysis that technology should be considered anthropomorphically (attributing human characteristics or behaviour to an object or aspect) in creating alternative non-venue-based assessments at ODeL institutions.

\section{DISCUSSION}

Stakeholder theory was used as a theoretical underpinning in this article and the technology and legitimacy themes were considered as theoretical lenses. At a theoretical level, the findings of this article contribute to the existing body of knowledge by focusing on the use of technologyenhanced alternative non-venue-based summative assessment in ODeL. In the past, we have seen technology as driving our day-to-day workings or innovations. During the interpretation of this article's data, technology is depicted as much more robust. The participants in the study contributed to the results since the themes that resulted from the data analysis, inter alia highlighted the importance of technology in an online environment. Although the interviewees indicated that they make use of non-venue-based formative assessments, it was evident from the data analysis that technology should also be considered as an anthropomorphic stakeholder in an ODeL institution, when summative alternative non-venue-based assessments are considered.

The 4IR and the swift move to the 5IR could result in a lack of trust in technology (Lindsay and Hudson 2019) and the availability thereof. Various participants in the study have raised concerns regarding the availability of technology, specifically during summative assessments:

"Do we have the technology to do it? Do we have the measures in place to control it?"

"I can tell you that a big portion of South Africa do not have internet."

"The main concern I have is access [to technology] on the one hand and then honesty."

The validity of summative assessments is therefore dependent on the academic integrity and specifically identity verification of students in non-venue-based assessments. This will have a considerable influence on the legitimacy and accreditation of qualifications and confirm the view of technology as an anthropomorphic stakeholder in an institution. This was confirmed by participants in the study, who commented as follows:

"What are the risks, how are we going to control that, what are we going to put in place? How are we going to make it a better option for them to comply, easier to comply, easier to do the right thing?"

"The world is changing so fast ... we have to be connected and share information."

"With the technology in place, students can speed up the process of their learning. As soon as you 
feel that you have mastered the contents of the module you can $\log$ on ... do the assessment and if you pass, you can move on to the next one."

"If we could ensure that they cannot open any other document and if we know someone is watching them while they do it then it is a fantastic option ...."

“... the concept [non-venue-based summative alternative assessment] needs to be monitored, needs to be in such a way that we can make sure that it is the student's attempts."

"I think they [professional bodies] ... will have a problem with non-venue-based assessments ... because they think it is not verifiable. You cannot place the body behind the work that has been done."

Most of the ODeL lecturers who participated in this study prefer to make use of innovative methods to assess a variety of skills and the students' experience in a real-world context. Students must have access to technology to obtain competency skills as required by professional accounting bodies, as stated by interviewees:

"[They must have] access to the technology so that you can actually say this is the only way that we are going to identify you. ... The biggest challenge is that a big portion of South Africa do not have internet and ... we are excluding all those students already. There ... is an ethical side to it." “... every student basically creates their own audit file where they have to identify the risk and then plan the audit program and then actually execute it on a computer and then write an audit report at the end with their findings, overall report and a detailed report. So it is very practically, what they will find in practice."

These verbatim examples clearly show that although technology is an essential stakeholder in the assessment process, it comes with many challenges.

The influence of technology in alternative non-venue-based assessments is critical and predominant. As technology functions in the same way as a human stakeholder, it should be treated anthropomorphically considering its powerful role. Technology should therefore be considered a stakeholder, especially if the attributes of power, legitimacy and urgency are present, according to Mitchell's model (Mitchell et al. 1997). This view of stakeholder theory has not been theorised thus far and is offered for future considerations as well as for its applied usage in the context of summative alternative non-venue-based assessments.

The researchers assert that the instrumental power of technology should be placed hierarchically in line with human stakeholders. When considering this premise, innovative spaces are opened up for the advancement of the Internet of Things and the 4IR as well as the 5IR (GSMA 2014). Some of the participants specifically referred to innovative methods that can be used with alternative assessments: 
"You could have a fingerprint of a student that you could link to their student number and then [with an] online assessment ... it is almost like their passcode to start the assessment or to download it and when they upload [the assessment use the] fingerprint again."

"Most of our students ... do not actually print it out, they answer it straight from their cell phones."

"Some of them have that camera scanner program on some of these phones where they can basically take a picture of the work that they have done so [they photograph] each and every page and they put this document together and they email it back to us."

"There is so much of artificial intelligence with regards to the marking that can even make our lives much easier in the future."

"[I have heard of] drones monitor[ing] the activity of students in exams ... [thereby replacing the] duty of invigilating the students."

All these aspects could provide an enabling environment for technology-enhanced assessment, but the academic integrity of summative assessments should be constantly considered to ensure the legitimacy of qualifications offered by the ODeL institution.

\section{Accounting Sciences Assessment Framework}

Due to the importance of technology as a stakeholder in alternative non-venue-based assessments in an ODeL environment, a final framework was compiled in the context of stakeholder theory with the themes that resulted from the empirical data. The symmetrical bidirectional arrows in Figure 1 indicate a two-way relationship that reinforces the linkage between the aspects. From the empirical data, the various aspects addressed in the framework are as follows:

- "ODL institution" refers to "distance education environment", "ODL" and "ODeL".

- "Alternative assessment" specifically refers to alternative non-venue-based assessments, which is an alternative to traditional venue-based examinations.

- The impact of 4IR and 5IR on technology and innovation was highlighted.

- "Identity verification" and the relationship with technology and innovation were specifically addressed to indicate the importance of legitimising qualifications in an ODeL institution.

- The different stakeholders have been identified in the framework, namely governing and regulating bodies, professional accountancy bodies, ODeL lectures and students.

- Students were incorporated as being in a direct and symmetrical relationship with alternative non-venue-based assessments. This highlights student-centredness as a key element of the framework.

- Due to the prominence of technology, it is indicated as a separate stakeholder. As an 
anthropomorphic stakeholder, technology now almost takes on the role of being "human" in that it does or could function in a manner that humans do.

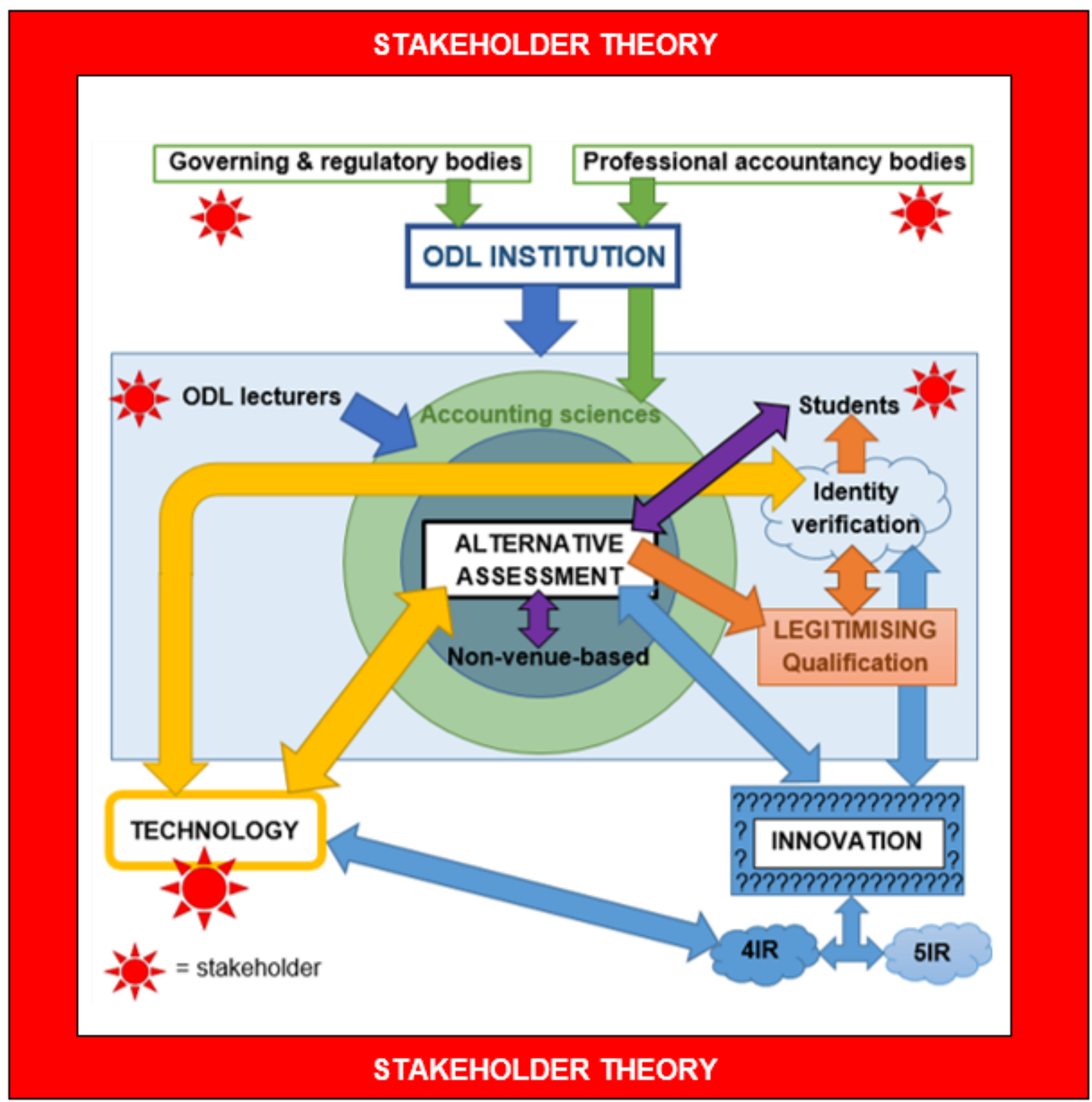

Figure 1: Alternative assessment framework developed depicting the application of the theory. (Source: Compiled by the authors)

The accounting sciences alternative assessment framework as illustrated in Figure 1, demonstrates how stakeholder theory creates improved performance and the potential for innovation to ensure the validation of qualifications offered by an ODeL institution. The various stakeholders in an ODeL institution were indicated as well as its influence on the framework and/or each other. Due to the important role of technology in the ODeL environment, it became clear that technology should be anthropomorphically considered a stakeholder in the ODeL institution. 


\section{CONCLUSION}

The number of registered students in distance education requires an innovative technologysupported environment. A core component for delivering successful graduates necessitates the improvement of retention rates, pass rates and throughput. Therefore, the effectiveness of teaching and assessing a large number of students in a technology-enhanced environment is crucial to ensure the legitimacy of qualifications offered by universities. In this article, an alternative assessment framework demonstrated the importance of technology, as a stakeholder in alternative non-venue-based assessments for undergraduate accounting sciences modules, in an ODeL environment.

This framework can contribute to the effective use of both formative and summative assessments in an ODeL or any other online or non-venue-based environment. It can also be used in other disciplines in higher education. These findings contribute to the body of knowledge and the fact that technology should be considered as an anthropomorphic stakeholder in creating, improving or restructuring an online educational institution due to its importance for conducting alternative non-venue-based assessments. Therefore, by embracing technology as a stakeholder in higher education, opportunities are presented for innovation and the advancement of the Internet of Things, the 4IR and 5IR. Further research studies in this area are of the utmost importance to realise the potential of technology-enhanced teaching and learning.

\section{REFERENCES}

ACCA see Association of Chartered Certified Accountants.

Alexiou, A. and F. Paraskeva. 2010. "Enhancing self-regulated learning skills through the implementation of an e-portfolio tool." Procedia-Social and Behavioural Sciences 2: 3048-3054.

Amigud, A., J. Arnedo-Moreno, T. Daradoumis, and A. Guerrero-Roldan. 2017. "Using learning analytics for preserving academic integrity." International Review of Research in Open and Distributed Learning 18(5): 192-210.

Arnold, I. J. M. 2016. "Cheating at online formative tests: Does it pay off?" The Internet and Higher Education 29: 98-106.

Association of Chartered Certified Accountants. 2019a. "CBE invigilator guidelines." https://secure. accaglobal.com/content/dam/ACCA Global/Learning\%20Providers/cbe/world/invigilatorguidelines-sept-2015.pdf (Accessed 20 June 2019).

Association of Chartered Certified Accountants. 2019b. "Your journey starts here." https://www.acca global.com/content/dam/ACCA_Global/Students/getting-started/ACCA\%20Student\%20 Welcome\%20Pack.pdf (Accessed 31 July 2019).

Barbour, R. S. 2001. "Checklists for improving rigour in qualitative research: A case of the tail wagging the dog?" British Medical Journal 322(7294): 1115-1117.

Bjørkquist, C. 2009. Stakeholder influence in higher education. Karlstad: Universitetstryckeriet.

Buchanan, T. 2000. "The efficacy of a world-wide web mediated formative assessment." Journal of 
Computer Assisted Learning 16(3): 193-200.

Braun, V. and V. Clarke. 2012. "Thematic analysis." In APA handbook of research methods in psychology, Vol. 2. Research designs: Quantitative, qualitative, neuropsychological and biological, ed. H. Cooper, P. M. Camic, D. L. Long, A. T. Panter, D. Rindskopf, and K. J. Sher, 57-71. Washington, DC: American Psychological Association.

Brinkmann, S. and S. Kvale. 2015. Interviews: Learning the craft of qualitative research interviewing. $3^{\text {rd }}$ Edition. Thousand Oaks, CA: Sage.

Carroll, J. and J. Appleton. 2001. "Plagiarism: A good practice guide." Oxford Brookes University. https://i.unisa.edu.au/siteassets/staff/tiu/documents/plagiarism---a-good-practice-guide-byoxford-brookes-university.pdf (Accessed 1 January 2018).

Chartered Institute of Management Accountants. 2018. "Assessment." https://www.cimaglobal.com/ Qualifications/Professional-Qualification/Assessment/ (Accessed 24 May 2018).

Chaudhary, S. V. S. and N. Dey. 2013. "Assessment in open and distance learning system (ODL): A challenge." Open Praxis 5(3): 207-216.

CHE see Council on Higher Education.

CIMA see Chartered Institute of Management Accountants.

Clarke, V. and V. Braun. 2017. "Thematic analysis.” The Journal of Positive Psychology 12(3): 297298.

Council on Higher Education. 2014. Distance higher education programmes in a digital era: Good practice guide. Pretoria: CHE.

Creswell, J. W. 2005. Educational research - planning, conducting and evaluating quantitative and qualitative research. Upper Saddle River: Pearson Prentice Hall.

Daffin, L. W. Jr. and A. A. Jones. 2018. "Comparing student performance on proctored and nonproctored exams in online Psychology courses." Online Learning Journal 22(1): 131-145.

De Lisle, J. 2015. "The promise and reality of formative assessment practice in a continuous assessment scheme: The case of Trinidad and Tobago." Assessment in Education: Principles, Policy \& Practice 22(1): 79-103.

Denscombe, M. 2003. The good research guide for small-scale social research projects. Maidenhead: Open University Press.

DHET see South Africa. Department of Higher Education and Training.

Dunn, K. E. and S. W. Mulvenon. 2009. "A critical review of research on formative assessment: The limited scientific evidence of the impact of formative assessment in education." Practical Assessment, Research \& Evaluation 14(7): 1-11.

Eloff, A. 2016. "The integration of information and information technology in accounting education: Effects on student performance." Journal of Economic and Financial Sciences 9(2): 409-425.

Fengliang, L. 2018. "The expansion of higher education and the returns of distance education in China." International Review of Research in Open and Distributed Learning 19(4): 243-256.

Fisher, E., A. J. McLeod, A. Savage, and M. G. Simkin. 2016. "Ghostwriters in the cloud." Journal of Accounting Education 34: 59-71.

Freeman, R. 1984. Strategic management: A stakeholder approach. Boston, MA: Pitman.

Goldkuhl, G. 2012. "Pragmatism vs interpretivism in qualitative information systems research." European Journal of Information Systems 21(2): 135-146.

Groupe Speciale Mobile Association. 2014. "Understanding the Internet of Things (IoT)." https://www.gsma.com/iot/wp-content/uploads/2014/08/cl_iot_wp_07_14.pdf (Accessed 8 May 2018).

GSMA, see Groupe Speciale Mobile Association.

Hylton, K., Y. Levy, and L. P. Dringus. 2016. "Utilising webcam-based proctoring to deter misconduct 
in online exams." Computers \& Education 92/93: 53-63.

Isaksson, S. 2008. "Assess as you go: The effect of continuous assessment on student learning during a short course in archaeology." Assessment and Evaluation in Higher Education 33(1): 1-7.

Jones, K. O., J. Reid, and R. Bartlett. 2008. "Cyber cheating in an information technology age." Digithum 10: 19-26.

Khanyile, M. 2018. "Essentiality of stakeholder management for university survival." South African Journal of Higher Education 32(4): 132-148.

Khare, A. and H. Lam. 2008. "Assessing student achievement and progress with online examinations: Some pedagogical and technical issues." International Journal on E-learning 7(3): 383-402.

Kruger, S. J. 2018. "Students' and lecturers' perception of the effect of open-book examinations on teaching and assessment at Departments of Accountancy at South African universities." South African Journal of Higher Education 32(5): 66-85.

Leisyte, I. and D. F. Westerheijden. 2014. "Stakeholders and quality assurance in education." In Drivers and barriers to achieving quality in higher education, ed. H. Eggins, 83-97. Durham: Springer.

Lincoln, Y. S. and E. G. Guba. 1985. Naturalistic inquiry. Newbury Park, CA: Sage.

Lincoln, Y. S. and E. G. Guba. 2013. The constructivist credo. Walnut Creek, CA: Left Coast Press.

Lindsay, J. and A. Hudson. 2019. "What is the fifth industrial revolution and how will it change the world?" Metro 10 June. https://metro.co.uk/2019/06/10/fifth-industrial-revolution-will-changeworld-9738825/ (Accessed 10 June 2019).

Marriot, P. 2009. "Students' evaluation of the use of online summative assessment on an undergraduate financial accounting module." British Journal of Educational Technology 40(2): 237-254.

Mason, J. 2018. Qualitative researching. $3^{\text {rd }}$ Edition. Thousand Oaks, CA: Sage.

Meyen, E. L., R. J. Aust, Y. N. Bui, and R. Isaacson. 2002. "Assessing and monitoring student progress in an e-learning personnel preparation environment." Teacher Education and Special Education 25(2): 187-198.

McChlery, S. and S. Visser. 2009. "A comparative analysis of the learning styles of accounting students in the United Kingdom and South Africa." Research in Post-compulsory Education 14(3): 299315.

McNiff, J. 2020. "Action research for professional development. What is action research?" http://www.jeanmcniff.com/ar-booklet.asp (Accessed 1 March 2020).

Mishra, A. and D. Mishra. 2013. "Applications of stakeholder theory in information systems and technology." Inzinerine Ekonomika-Engineering Economics 24(3): 254-266.

Mitchell, K., B. Agle, and J. Wood. 1997. "Toward a theory of stakeholder identification and salience: Defining the principle of who and what really counts." Academy of Management Review 22(4): 853-886.

Mitroff, II. 1983. Stakeholders of the organizational mind. San Francisco, CA: Jossey-Bass.

Moodle. 2019. "Plagiarism." https://moodle.org/plugins/browse.php?list=category\&id=35 (Accessed: 26 October 2019).

Mouton, J. 2001. How to succeed in your master's and doctoral studies. Pretoria: Van Schaik.

NASBA see National Association of State Boards of Accountancy.

National Association of State Boards of Accountancy. 2016. "CPA exam FAQ." https://www.nasba.org/ exams/cpaexam/examfaq/\#scheduling (Accessed 6 October 2016).

Norcini, J. J., R. Lipner, and S. M. Downing. 1996. "How meaningful are scores on a take-home recertification examination?" Academic Medicine 71(10) Suppl.: S71-S73.

Oraifige, A., D. Heesom, and A. Felton. 2009. "Technology supported learning (TSL) for formative assessment." Engineering Education 4(1): 61-67.

Padayachee, P., S. Wagner-Welsh, and H. Johannes. 2018. "Online assessment in Moodle: A framework 
for supporting our students." South African Journal of Higher Education 32(5): 211-235.

Palinkas, L. A., S. M. Horwitz, C. A. Green, J. P. Wisdom, N. Duan, and K. Hoagwood. 2015. Purposeful sampling for qualitative data collection and analysis in mixed method implementation research. Administration and Policy in Mental Health and Mental Health Services Research 42(5): $533-544$.

Parle, G. and G. K. Laing. 2017. "Investment portfolio simulation: An assessment task in finance." Ejournal of Business Education and Scholarship of Teaching 11(1): 118-126.

Patton, M. Q. 2015. Qualitative research and evaluation methods. $4^{\text {th }}$ Edition. Thousand Oaks, CA: Sage.

Pavela, G., D. L. McCabe, and D. McDuf. 2017. "Ten Principles of Academic Integrity for Faculty." https://integrityseminar.org/wp-content/uploads/2018/02/AIS-Ten-Principles-2017.pdf (Accessed 26 October 2019).

Pincus, K. V., D. E. Stout, J. E. Sorensen, K. D. Stocks, and R. A. Lawson. 2017. "Forces for change in higher education and implications for the accounting academy." Journal of Accounting Education 40: $1-18$.

Respondus. 2018. "Respondus monitor instructor resources." https://www.respondus.com/products/ monitor/resources.shtml (Accessed 14 May 2018).

Reyneke, Y. 2016. "The use of case studies for pervasive skills training in ODL accounting education." MPhil (Acc Sci) thesis. University of South Africa, Pretoria.

Rovai, A. P. 2000. "Online and traditional assessments: What is the difference?" The Internet and Higher Education 3(3): 141-151.

Rust, C. 2002. "The impact of assessment on student learning: How can the research literature practically help to inform the development of departmental assessment strategies and learner-centred assessment practices?" Active Learning in Higher Education 3(2): 145-158.

SAICA see South African Institute of Chartered Accountants.

Saldaña, J. 2016. The coding manual for qualitative researchers. $2^{\text {nd }}$ Edition. London: Sage.

Salmons, J. 2015. Qualitative online interviews. $2^{\text {nd }}$ Edition. Thousand Oaks, CA: Sage.

SAQA see South Africa. South African Qualifications Authority.

Saunders, M., P. Lewis, and A. Thornhill. 2016. Research methods for business students. $7^{\text {th }}$ Edition. Essex: Pearson.

Scully, D. 2017. "Constructing multiple-choice items to measure higher-order thinking." Practical Assessment Research and Evaluation 22(4): 1-13.

South Africa. Department of Higher Education and Training. 2013. "White Paper for Post-School Education and Training." http://www.dhet.gov.za/SiteAssets/Latest\%20News/White\%20paper\% 20for\%20post-school\%20education\%20and\%20training.pdf (Accessed 2 May 2016).

South Africa. Department of Higher Education and Training. 2014. "Policy for the provision of distance education in South African universities in the context of an integrated post-school system." Government Gazette, 37811, 7 July, 3-22.

South African Institute of Chartered Accountants. 2016. "Frequently asked questions about the assessment of professional competence (APC)." https://www.saica.co.za/Portals/0/Learners Students/Examinations/APC\%20FAQs.pdf (Accessed 21 June 2019).

South African Institute of Chartered Accountants. 2018. "Assessment of professional competence (APC) November 2018].” https://www.saica.co.za/Portals/0/LearnersStudents/Part\%20II\%20APC\% 20Nov\%202019\%20Candidate\%20Guidelines.pdf (Accessed 21 June 2019).

South Africa. South African Qualifications Authority. 2014. "National policy and criteria for designing and implementing assessment for NQF qualifications and part-qualifications and professional designations in South Africa." Government Gazette 38246, 28 November, 3-28.

Stack, S. 2015. "The impact of exam environments on student test scores in online courses." Journal of 
Criminal Justice Education 26(3): 273-282.

Subotzky, G and P. Prinsloo. 2011. "Turning the tide: A socio-critical model and framework for improving student success in open distance learning at the University of South Africa." Distance Education 32(2): 177-193.

Suchman, M. C. 1995. "Managing legitimacy: Strategic and institutional approaches." Academy of Management Review 20: 571-610.

Taylor, S, M. Ryan, and J. Pearce. 2015. "Enhanced student learning in accounting utilising web-based technology, peer-review feedback and reflective practices: A learning community approach to assessment." Higher Education Research \& Development 34(6): 1251-1269.

The World Bank. 2018. "World Bank country and lending groups - Country classification." https://datahelpdesk.worldbank.org/knowledgebase/articles/906519-world-bank-country-andlending-groups (Accessed 1 January 2018).

Tung, L. C. 2012. "Proactive intervention strategies for improving online student retention in a Malaysian distance education institution." Merlot Journal of Online Learning and Teaching 8(4): 312-323.

UNESCO Institute for Statistics. 2019. "Databank: Education statistics - all indicators." https://databank.worldbank.org/reports.aspx?source=education-statistics- -all-indicators\# (Accessed 29 July 2019).

Van Rooyen, A. 2015. "Distance education accounting students' perceptions of social media integration." Procedia - Social and Behavioural Sciences 176: 444-450.

Von Grünigen, D., F. Benites de Azevedo e Souza, B. Pradarelli, A. Magid, and M. Cieliebak. 2018. "Best practices in e-assessment - with a special focus on cheating prevention." Proceedings of the IEEE Global Engineering Education Conference (EDUCON): Emerging trends and challenges of engineering education, Santa Cruz de Tenerife, Canary Islands, Spain, April 17-20. IEEE Xplore ${ }^{\circledR}$. 893-899.

Waghid, Y. and N. Davids. 2019. "On the polemic of academic integrity in Higher Education." South African Journal of Higher Education 33(1): 1-5.

Wang, S. and H. Hsu. 2008. "Use of the webinar tool (Elluminate) to support training: The effects of webinar-learning implementation from student-trainers' perspective." Journal of Interactive Online Learning 7(3): 175-194.

Watwood, B., J. Nugent, and W. Deihl. 2009. "Online teaching and learning resource guide." VCU Centre for Teaching Excellence. http://www.uwec.edu/CETL/resources/upload/onlineassessment.pdf (Accessed 6 September 2016).

WEF, see World Economic Forum.

World Economic Forum. 2016. "South Africa has a skills shortage. How do we fix it?" https://www.weforum.org/agenda/2016/05/south-africa-skills-shortage-how-do-we-fix-it/ (Accessed 8 November 2017).

Xu, X., S. Kauer, and S. Tupy. 2016. "Multiple-choice questions: Tips for optimizing assessment inseat and online." Scholarship of Teaching and Learning in Psychology 2(2): 147-158. 